\title{
CLINICAL AND RADIOLOGIC APPROACH TO PROBABLE MIXED DEMENTIA (VASCULAR DEMENTIA AND PROGRESSIVE SUPRANUCLEAR PALSY)
}

\author{
Diatri Nari Lastri ${ }^{1}$, Ahmad Sulaiman Alwahdy ${ }^{1}$ \\ Correspondence: diatri.neurologi@gmail.com \\ ${ }^{1}$ Department of Neurology Faculty of Medicine Universitas Indonesia, Depok, Indonesia.
}

\author{
Article History: \\ Received: Mei 2, 2019 \\ Accepted: December 20, 2019 \\ Published: January 1, 2020

\section{Cite this as:} \\ Lastri DN, Sulaiman A, Alwahdy. \\ Clinical and radiologic approach \\ to probable mixed dementia \\ (vascular dementia and \\ progressive supranuclear palsy). \\ Malang Neurology Journal; \\ 2020.6:46-40. \\ http://dx.doi.org/10.21776/ub.mnj \\ .2020.006.01.10
}

\section{ABSTRACT}

Dementia as a global burden neurodegenerative disease need to be diagnosed as earlier as possible then treated accordingly. The varying aetiologies of dementia render specific diagnosis of dementia challenging. Other than clinical syndromes, cognitive function examination and neuroimaging are also important to determine the correct dementia diagnosis. This paper aims to provide a dementia case where the working diagnosis could not be decided at once and to show how cognitive function examination and neuroimaging are essential to determine the diagnosis. This paper reports an 80-year old male with dementia symptoms that was followed and regularly examined for one year. With time, additional neurological symptoms were observed thus the working diagnosis was established. The patient was diagnosed with mixed dementia that consisted of probable vascular cognitive impairment and probable progressive supranuclear palsy.

Keywords: vascular cognitive impairment, progressive supranuclear palsy, cognitive function examination, MRI, dementia

\section{Introduction}

Dementia is an extensively growing degenerative disease hence rendering it as a global burden. Currently there are least 50 million people are suffering from dementia and the number will heighten with age increment. Unfortunately, the diagnosis of dementia is difficult and complex since there are various etiology and the clinical manifestations may be progressive for years or fluctuating. ${ }^{1}$

This case report will deliver a patient with an initial diagnosis vascular dementia, but with time he experienced typical sign of progressive supranuclear palsy (PSP) such as upper gaze palsy. With the new typical signs and radiologic image, probable mixed dementia (vascular dementia and PSP) can be confirmed. The purpose of this case report is to inform readers how clinical signs, including non-cognitive functions, may be a clue for neurologists to conclude a diagnosis which later will affect patients' treatment and prognosis.

\section{Case Report}

An 80-year old male with Parkinson's Disease and differential diagnosis vascular dementia was referred to neurologic clinic in Cipto Mangunkusumo General Hospital (RSCM) for cognitive function tests. One year prior, he was presented with forgetfulness. At first, it was only forgetting where he put things, but later on he forgot prayer words and kept repeating conversations. He tended to walk fast and was difficult to stop. There was visual hallucination and sometimes auditory hallucination. The patient had MRI in RSCM and was said to have stroke then was given risperidone $2 \times 0.5 \mathrm{mg}$ by a psychiatrist.
Six months after, there were new symptoms such as falling (it occured when the patient was standing up after sitting and after he hit objects while walking), slower movement, and frequent choking and coughing but improvement in both visual and auditory hallucination. He was diagnosed with postural hypotension in Harapan Kita General Hospital for his falling during position change. The frequent choking and coughing were assessed as the side effect of risperidone; hence the antipsychotic was planned to be changed.

There was a 10-year history of well-controlled hypertension. There was a history of stroke but no diabetes mellitus, head trauma, cardiovascular disease, or kidney abnormality. There was no family history of hypertension, diabetes mellitus, stroke, or cardiovascular disease. The patient was married with six children and currently is not working. He lived with two of his children.

The patient was fully alert, vital signs and general examinations were normal. His face was expressionless. On cranial nerve examination, there was upper gaze palsy. Motor examination of four extremities, sensory examination, and autonomic examination were normal. There was neither intention nor resting tremor but there was bradykinesia on bilateral arms. Romberg test and retropulsion test were normal.

Non-contrast head MRI and cognitive function test were conducted on the patient. The result of MRI (Figure 1) showed periventricle leukoencephalopathy, cerebralatrophy with deep white matter ischemia (Fazekas grade III), and humming bird appearance. 


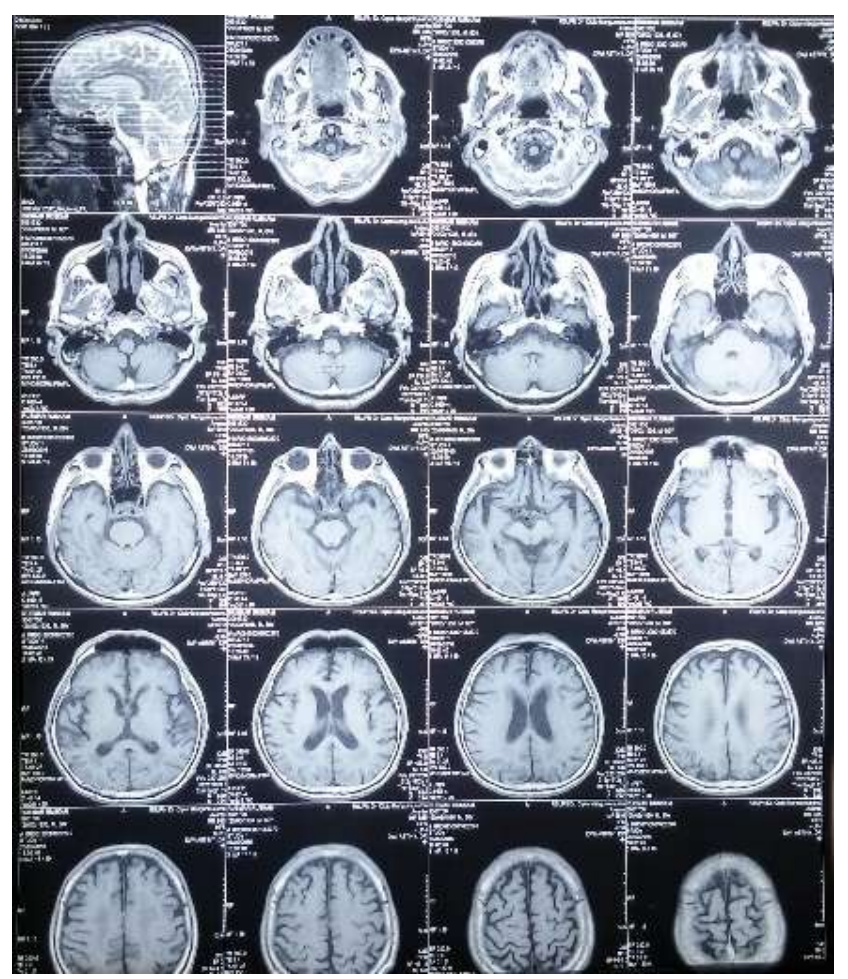

(a)

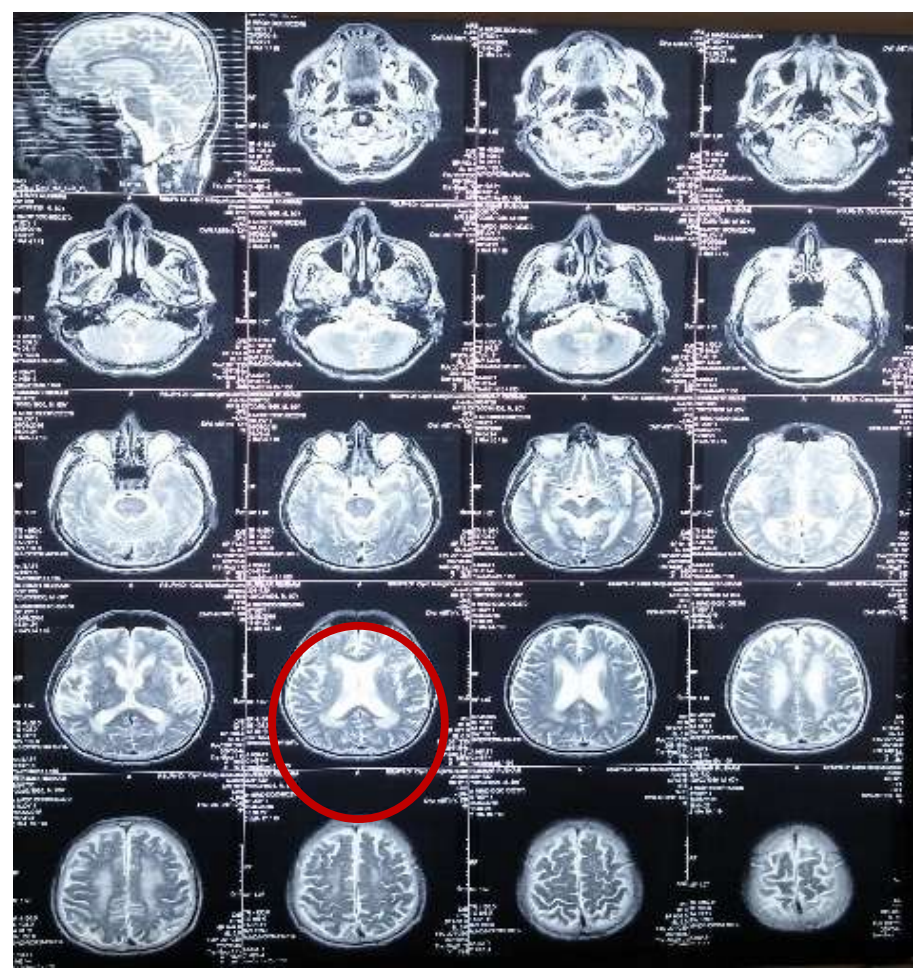

(b)

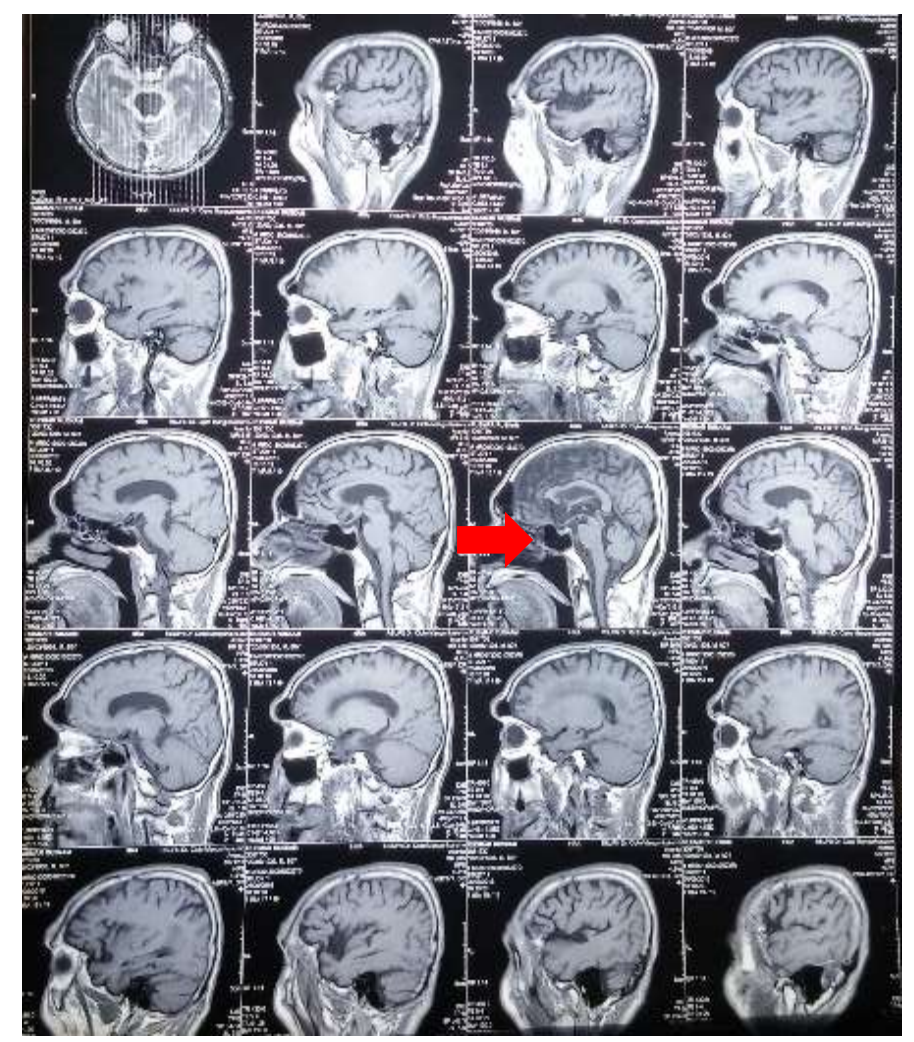

(c)

Figure 1. Non-contrast head MRI, a) T1WI axial slice, b) T2WI axial slice with bilateral periventricle white matter lesion (red circle), c) T1WI sagittal slice with hummingbird sign

Cognitive function tests were conducted twice on September 2016 and after one year. Both of the results are presented in table 1 as a comparison.

Based on the history taking and examinations above, it can be concluded that the patient had following diagnosis. Clinical diagnosis are upper gaze palsy, parkinsonism, psychomotor slowing, recent memory impairment, delayed auditory memory impairment, executive function impairment, and visuospatial impairment, topical diagnosis are subcortex and midbrain, etiological diagnosis are vascular and idiopathic, Pathological diagnosis are ischemia and suspected taupathy. 
Table 1. Cognitive function tests

\begin{tabular}{|c|c|c|}
\hline Examination & Beginning & After one year \\
\hline $\begin{array}{l}\text { Neuropsychiatry } \\
\text { sign }\end{array}$ & $\begin{array}{l}\text { Visual and auditory } \\
\text { hallucination }\end{array}$ & $\begin{array}{l}\text { Visual and auditory } \\
\text { hallucination } \\
\text { (improvement) }\end{array}$ \\
\hline Attention & Intact, digit span: 6 & Intact, digit span: 6 \\
\hline Orientation & Good & Good \\
\hline Concentration & $\begin{array}{l}\text { Letter A test MoCA- } \\
\text { Ina: good }\end{array}$ & $\begin{array}{l}\text { Letter A test MoCA-Ina: } \\
\text { good }\end{array}$ \\
\hline Working Memory & $\begin{array}{l}\text { Backward digit span: } \\
3\end{array}$ & Backward digit span: 3 \\
\hline \multicolumn{3}{|l|}{ Language } \\
\hline Speaking & Spontaneous & Spontaneous, slow \\
\hline $\begin{array}{l}\text { Verbal } \\
\text { understanding }\end{array}$ & Intact & Intact \\
\hline Naming & Mildly impaired & Good \\
\hline Repeating & 7 words & 7 words \\
\hline Reading and writing & Good & Good \\
\hline \multicolumn{3}{|l|}{ Memory } \\
\hline Immediate memory & Good & Good \\
\hline $\begin{array}{l}\text { Recent Auditory } \\
\text { Memory }\end{array}$ & Good & Good \\
\hline $\begin{array}{ll}\text { Recent } & \text { Visual } \\
\text { Memory } & \end{array}$ & Impaired & Impaired \\
\hline Remote Memory & Intact & Intact \\
\hline \multicolumn{3}{|l|}{ CERAD } \\
\hline Trial $1 / 2 / 3$ & $0 / 2 / 4$ & $3 / 7 / 6$ \\
\hline $\begin{array}{l}15 \text { Boston naming } \\
\text { test }\end{array}$ & $14 / 15$ & $12 / 15$ \\
\hline Verbal fluency & $10 /$ minutes & 8/minutes \\
\hline $\begin{array}{l}\text { Visuoconstructive } \\
\text { ability } \\
\text { (Constructional } \\
\text { Praxis Test) }\end{array}$ & $11 / 11$ & $11 / 11$ \\
\hline Delayed memory & $0 / 10$ & $3 / 10$ \\
\hline Recognition & $1 / 10,0 / 0$ & $7 / 10,0 / 0$ \\
\hline \multicolumn{3}{|l|}{ Executive Function } \\
\hline Calculation & Good & Good \\
\hline Abstraction & Good & Good \\
\hline TMT A & $\begin{array}{l}1 \text { minutes } 57 \\
\text { seconds }\end{array}$ & 2 minutes 12 seconds \\
\hline TMT B & Impaired & Impaired \\
\hline \multicolumn{3}{|l|}{ Visuospatial Function } \\
\hline Visuoperception & Good & $\begin{array}{l}\text { Unable to draw 3- } \\
\text { dimension figure }\end{array}$ \\
\hline Visuoconstruction & Good & $\begin{array}{l}\text { Unable to draw 3- } \\
\text { dimension figure }\end{array}$ \\
\hline Emotion & Stable & Stable \\
\hline MMSE & $28 / 30$ (recall 1/3) & $\begin{array}{l}26 / 30(\text { recall } 0 / 3 \text {, } \\
\text { calculation } 4 / 5)\end{array}$ \\
\hline MoCA-Ina & $\begin{array}{l}23 / 30 \text { (naming } 2 / 3 \text {, } \\
\text { verbal fluency } 0 / 1, \\
\text { delayed memory } 0 / 5 \text { ) }\end{array}$ & $\begin{array}{l}24 / 30 \text { (delayed memory } \\
1 / 5, \text { visuospatial } 0 / 1, \\
\text { verbal fluency } \mathbf{0} / \mathbf{1} \text { ) }\end{array}$ \\
\hline ADL/IADL & $\begin{array}{l}\text { Partially assisted by } \\
\text { family }\end{array}$ & $\begin{array}{l}\text { Partially assisted by } \\
\text { family }\end{array}$ \\
\hline Conclusion & $\begin{array}{l}\text { Mild naming } \\
\text { impairment, delayed } \\
\text { auditory memory } \\
\text { impairment, } \\
\text { executive function } \\
\text { impairment which } \\
\text { may be fitting } \\
\text { vascular cognitive } \\
\text { impairment. }\end{array}$ & $\begin{array}{l}\text { Probable mixed } \\
\text { dementia (progressive } \\
\text { supranuclear palsy and } \\
\text { vascular dementia) can } \\
\text { be concluded based on } \\
\text { following findings: } \\
\text { upper gaze palsy, } \\
\text { parkinsonism, } \\
\text { psychomotor slowing, } \\
\text { recent memory } \\
\text { impairment with intact } \\
\text { recognition, and } \\
\text { visuocontructive } \\
\text { impairment that causes } \\
\text { dysfunction. }\end{array}$ \\
\hline
\end{tabular}

\section{Discussion}

From the patient's symptoms one year prior to diagnosis, vascular cognitive impairment should be suspected based on a history of stroke and cognitive impairment (memory, executive function, and language impairment). It was then supported by imaging evidence of white matter lesion from T2WI MRI showing periventricle leukoencephalopathy. White matter hyperintensities (WMH), according to Wardlaw et $\mathrm{al}^{2}$, are of vascular origin and part of small vessel disease spectrum. WMH increases with vascular risk factor, such as smoking, diabetes, hypertension, and other yet undetermined risk factors. The clinical implication of WMH is that it is an important markers of increased risk of dementia, especially vascular dementia. Hence, the diagnostic criteria for vascular cognitive impairment had been fulfilled. Since the diagnosis was supported by both clinical picture and imaging evidence, the level of certainty should be probable. ${ }^{3}$

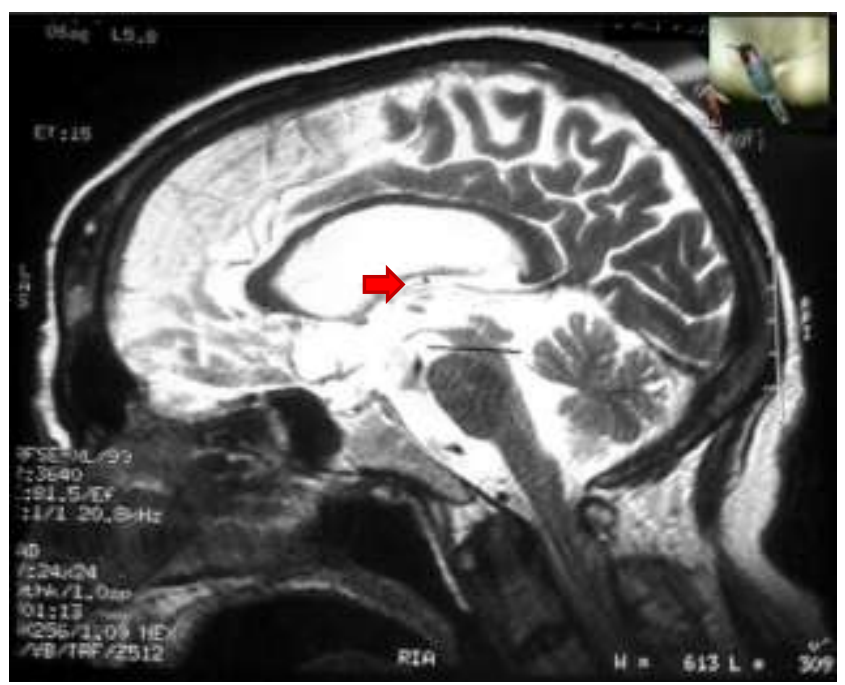

Figure 2. A T2-weighted MRI image showing Hummingbird sign (above the black line) ${ }^{13}$

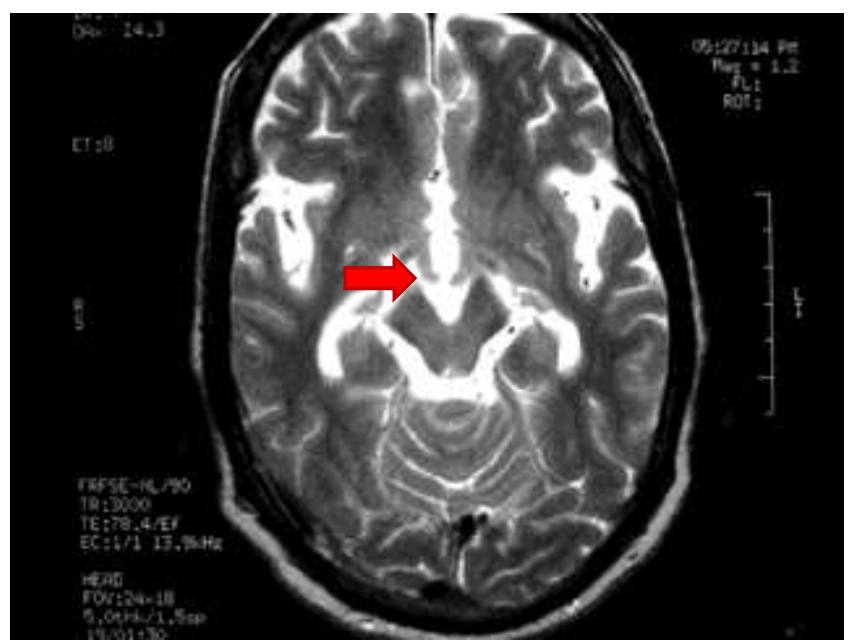

Figure 3. An axial T2-weighted MRI image showing morning glory sign or Mickey Mouse sign ${ }^{13}$

In order to make a more certain diagnosis, other differential diagnosis must be excluded. Delirium from metabolic causes, Alzheimer's disease (AD), and Parkinson's Dementia Disease (PDD) were possible diagnosis when looking at the initial symptoms. Delirium from metabolic 
causes could be excluded as laboratory tests were within normal range. $\mathrm{AD}$ was unlikely since there should not be focal neurological deficit and this patient's memory impairment was not the most predominant symptom. Psychiatric symptoms in $\mathrm{AD}$ are usually in the form of depression, anxiety, and delusion. In addition, patient's Hachinski ischemic score was 8 which suggested vascular as a more possible etiology. ${ }^{4}$ PDD was less likely because predominant cognitive impairment in PDD should be attention, executive function, and visuospatial, meanwhile this patient had an intact attention. ${ }^{5}$

One year after the initial symptoms, the patient once again was presented with new signs and symptoms, namely frequent falling, even slower movements, choking, coughing, and upper gaze palsy yet there was improvement on the hallucination. They raised a question whether vascular cognitive impairment was the correct diagnosis or there was another condition. The new clinical findings (especially the worsening visuospatial function and upper gaze palsy) were most likely completing the previous symptoms thus constructing PSP diagnosis. ${ }^{6}$

The patient fulfilled PSP inclusion diagnostic criteria by MDS-PSP (Movement Disorder Society-Progressive Supranuclear Palsy), namely sporadic occurrence, onset above 40 years old, and gradual progression of symptoms, and did not fulfil the exclusion criteria. Core clinical features in this patient are O1 (vertical supranuclear gaze palsy), P1 (repeated unprovoked falls within three years), A2 (parkinsonism and levodopa resistant), and C1 (language disorder). Akinesia domain was still debatable between A2 or A3 since no levodopa challenge was given thus sensitivity to levodopa remained unknown. Degree of diagnosis may vary based on clinical symptoms. The combination of $\mathrm{O} 1$ and $\mathrm{P} 1$ resulted in probable PSP with Richardson's syndrome. The combination of $\mathrm{O} 1$ and $\mathrm{A} 2$ or A3 resulted in probable PSP with predominant parkinsonism. The combination of $\mathrm{O} 1$ and $\mathrm{C} 1$ resulted in possible PSP with predominant speech/language disorder. ${ }^{7}$

The patient's frequent choking and coughing may be caused by the use of risperidone. Dysphagia is an uncommon side effect of antipsychotic especially typical antipsychotic. In another case report by Lee et al, they mention haloperidol and risperidone as the cause of their patient's dysphagia. Therefore in the future, antipsychotic medications must be strictly monitored especially in demented patients. ${ }^{8}$

Hummingbird sign results from rostral midbrain tegmentum atrophy causing a concavity as the head of Hummingbird. Figure 2 explains the midbrain tegmentum atrophy (above the black line) while preservation of pons (under the black line). The specificity and positive predictive value of this sign are $99.5 \%$ and $96.1 \%$ correspondingly yet low sensitivity of $51.6 \% .^{12,13}$

\section{Vascular Cognitive Impairment}

According to American Heart Association and American Stroke Association (AHA/ASA), vascular cognitive impairment VCI is "a syndrome with evidence of clinical stroke or subclinical vascular brain injury and cognitive impairment affecting at least one cognitive domain." Risk factors of developing VCI include increasing age, low education, female, history of stroke, global and medial temporal atrophy (found from neuroimaging), late life depression, and vascular risk factors, namely hypertension, smoking, history of ischemic heart disease, dyslipidemia, atrial fibrillation, diabetes mellitus, and obesity. ${ }^{9}$

VCI diagnosis may be difficult to be made based on clinical syndrome only, although certain cognitive functions tend to be impaired in VCI, such as attention, information processing, and executive function. Neuroimaging evidence is required to establish VCI diagnosis. Although CT scan is sufficient, MRI is highly preferable since MRI enables the visualization of the location, extent, and degree of cerebrovascular disease. Significant findings may be many lacunes, infarcts, substantial burden of white matter lesions, or the combination of them. White matter lesion is special because previous studies mentioned it as a strong predictors of cognitive and functional impairment over the next 3 years. To determine the extent of cerebrovascular disease, brain atrophy (whether generalized, hippocampal, or both) should also be observed in neuroimaging. 2,10

\section{Progressive Supranuclear Palsy}

PSP was believed to be a type of atypical parkinsonism. With time it is discovered that PSP is one of 4-repeat tauopathies. In 1996, The National Institute of Neurological Disorders and Stroke validated neuropathological criteria required to diagnose PSP, which are neurofibrillary tangles or neuropil threads (tau protein) or both in basal ganglia and brainstem. In $\mathrm{AD}$, anatomical distribution of the tau pathology affects the clinical syndromes, similar occurrence is also observed in PSP. The tau pathology distribution variability then causes different phenotypes of PSP. ${ }^{6,11}$

Ante mortem diagnosis may be challenging since cognitive dysfunction may overlap with other dementia aetiologies or incomplete presentation. Imaging studies, especially MRI, has been used in several studies to assist PSP diagnosis. Significant imaging findings in PSP are hummingbird sign (figure 2) and morning glory sign (figure 3 ). ${ }^{12}$

Morning glory sign results from midbrain tegmentum atrophy and cerebral peduncles thinning causing a concavity of the lateral margin of midbrain tegmentum. The specificity of morning glory sign is $97.7 \%$ but the sensitivity is $36.8 \%$. $^{12,13}$

\section{Conclusion}

Dementia is a neurodegenerative disease with varying etiologies. Multiple dementia etiologies may occur in one patient; rendering mixed dementia to be considered. The patient in this case report could be diagnosed as mixed dementia which consisted of probable VCI and probable PSP based on continuing cognitive function examination and MRI. It is therefore suggested to conduct a routine cognitive function examination on demented patients to anticipate new neurological signs and/or symptoms thus allowing earlier diagnosis and treatment.

\section{Acknowledgement}

The authors would like to thank to patient, cipto Mangunkusumo Hospital, Faculty Medicine Universitas indonesia for facilitating this case report study. 


\section{References}

1. Patterson C. World Alzheimer report 2018: The state of the art of dementia research: new frontiers [Internet]. Alzheimer's Disease International; 2018. Available from: https://www.alz.co.uk/research/WorldAlzheimerRepor t2018.pdf

2. Wardlaw JM, Valdés Hernández MC, MuñozManiega S. What are white matter hyperintensities made of? Relevance to vascular cognitive impairment. J Am Heart Assoc; 2015. Jun;23;4(6):1140. DOI: 10.1161/JAHA.114.001140

3. Sachdev P, Kalaria R, O’Brien J, Skoog I, Alladi S, Black SE, et al. Diagnostic criteria for vascular cognitive disorders: a VASCOG statement. Alzheimer Dis Assoc Disord, 2014. Sep;28(3):206-18. DOI: 10.1097/WAD.0000000000000034.

4. Nadeau Y, Black SE. Mixed Dementia: The most common cause of dementia? Can J Diagn, 2010. Apr;35-44. DOI:10.1111/J/1749-6632.2002.TB04807

5. Poewe W, Gauthier S, Aarsland D, Leverenz JB, Barone $\mathrm{P}$, Weintraub $\mathrm{D}$, et al. Diagnosis and management of Parkinson's disease dementia. Int J Clin Pract, 2008. Oct;62(10):1581-7. DOI: 10.1111/j.1742-1241.2008.01869.x.

6. Boxer AL, Yu J-T, Golbe LI, Litvan I, Lang AE, Höglinger GU. Advances in progressive supranuclear palsy: new diagnostic criteria, biomarkers, and therapeutic approaches. Lancet Neurol, 2017. Jul;16(7):552-63. DOI: $\quad$ 10.1016/S14744422(17)30157-6.
7. Höglinger GU, Respondek G, Stamelou M, Kurz C, Josephs KA, Lang AE, et al. Clinical diagnosis of progressive supranuclear palsy: The movement disorder society criteria. Mov Disord Off J Mov Disord Soc; 2017.32(6):853-64. DOI: 10.1002/mds.26987

8. Lee JC, Takeshita J. Antipsychotic-Induced Dysphagia: A Case Report. Prim Care Companion CNS Disord; 2015.17(5). DOI:10.4088/PCC.15101792

9. Gorelick PB, Nyenhuis D. Understanding and Treating Vascular Cognitive Impairment: Contin Lifelong Learn Neurol, 2013. Apr;19(2):425-37. DOI: 10.1212/01.CON.0000429174.29601.de.

10. O'Brien JT, Thomas A. Vascular dementia. The Lancet, 2015. Oct;386(10004):1698-706. DOI: 10.1016/S0140-6736(15)00463-8.

11. Dickson DW, Ahmed Z, Algom AA, Tsuboi Y, Josephs KA. Neuropathology of variants of progressive supranuclear palsy: Curr Opin Neurol,. 2010. Aug;23(4):394-400. DOI: 10.1097/WCO.0b013e32833be924

12. Mueller C, Hussl A, Krismer F, Heim B, Mahlknecht $\mathrm{P}$, Nocker $\mathrm{M}$, et al. The diagnostic accuracy of the hummingbird and morning glory sign in patients with neurodegenerative parkinsonism. Parkinsonism Relat Disord, 2018. Sep;54:90-4. DOI: 10.1016/j.parkreldis.2018.04.005.

13. Sonthalia N, Ray S. The Hummingbird sign: a diagnostic clue for Steele-Richardson-Olszweski syndrome. BMJ Case Rep; 2012. DOI: 10.1136/bcr2012-006263. 